\title{
AVALIAÇÃO E PERCEPÇÃo DO USUÁRIO EM RELAÇÃO AO CONFORTO TÉRMICO E QUÁLIDÁ́DE DO AR EM VARANDAS COM FECHAMENTÓ EM VIDROS MÓVEIS SITUADAS EM UMA XREGIÃO URBANA INDUSTRIALIZADA
}

Evaluation and user's perception regarding the thermal comfort and ai quality in operable glazed balconies located in an urban industrialized region Erica Coelho Pagel' ${ }^{1}$ Cristina Engel de Alvarez ${ }^{2}$, Neyval Costa Reis Júnior ${ }^{3}$

RESUMO: Atualmente uma ação muito comum nas grandes metrópoles é o fechamento com vidros móveis das aberturas das varandas residenciais. Na cidade de Vitória, ES, é constante a reclamação dos moradores acerca da presença do pó preto em suas residências. O incômodo ocasionado pela presença desse material particulado é o principal motivador da prática do fechamento das varandas na região. O objetivo desta pesquisa foi avaliar a qualidade ambiental e a percepção do morador capixaba - em relação ao conforto térmico e a qualidade do ar, residente em apartamentos com e sem fechamento em vidros móveis nas aberturas de suas varandas. A partir da definição de critérios e da posterior escolha de um condomínio residencial estrategicamente localizado, a metodologia utilizada foi estabelecida considerando duas principais fontes de obtenção de dados e informações: os usuários, através da aplicação de questionários; e de medições em campo de temperatura do ar, umidade relativa do ar e concentração de material particulado. Os resultados mostram que a concentração média diária de partículas foi maior na situação da varanda com os vidros móveis fechados do que na condição aberta. Além disso, o uso dos vidros móveis das varandas a maior parte do tempo fechados ocasiona um aumento de temperatura do ar no ambiente e desconforto térmico, o que faz com que alguns moradores recorram ao uso do ar condicionado corrompendo o propósito original da varanda em climas quentes e úmidos, que é de trazer sombreamento e ventilação natural aos espaços interiores.

PALAVRAS-CHAVE: Avaliação ambiental; Edifício residencial; Varandas; Conforto térmico; Qualidade do ar.

\begin{abstract}
Currently, a very common action in large cities is closing the residential balconies with operable glass. In the city of Vitoria, ES, it is constant the residents' complaint about the presence of black dust in their residences. The nuisance caused by the presence of this particulate matter is the main motivator of the practice of closing balconies in the region. The aim of the present research was to evaluate the environmental quality and the Vitoria resident's perception - regarding the thermal comfort and air quality - who lives in apartments with and with no operable glazed balconies. From the setting of criteria and the subsequent choice of a strategically located residential condominium, the methodology used has been established considering two main sources of obtaining data and information: directly from users, through the application of questionnaires; and by field measurements of the air temperature, air relative humidity and concentration of particulate matter. The results show that the daily average concentration of particulates was higher in situation of the operable glazed balcony was closed than in the open condition. In addition, the use of operable glazed balconies, keeping them closed most of the time leads to increased air temperature in the environment and thermal discomfort, which causes some residents have recourse to the use of air conditioner, thus subverting the original purpose of the balcony in hot and humid climates, which is provide shading and natural ventilation to the interior spaces.
\end{abstract}

KEYWORDS: Environmental evaluation; Residential building; Balconies; Thermal comfort; Air quality.
How to cite this article:

PAGEL, E. C.: ALVAREZ, C. E.: REIS JÚNIOR, N. C. Avaliação e percepção do usuário em relação ao conforto térmico e qualidade do ar em varandas com fechamento em vidros móveis situadas em uma região urbana industrializada. Gestão e Tecnologia de Projetos, São Carlos, v.13, n.3, p.57-77, dez. 2018. http://dx.doi.org/10.11606/gtp. v13i3.148455
Fonte de financiamento: Declara não haver Conflito de interesse: Declara não haver Submetido em: 26/07/2018 Aceito em: 30/11/2018 


\title{
INTRODUÇÃO
}

O crescimento das cidades e os efeitos da poluição do ar decorrentes do processo de urbanização são detectados em diversas cidades do mundo. Devido à estas mudanças, a qualidade do ar tem sido um tema extensivamente pesquisado nas últimas décadas, caracterizando-se como um fator de grande importância na busca da preservação do meio ambiente e na implementação de um desenvolvimento alicerçado no conceito da sustentabilidade, considerando que seus efeitos afetam, de diversas formas, a saúde humana, os ecossistemas e os materiais (SPIRU; SIMONA, 2017). Entretanto, pouco se tem discutido sobre essa influência na modificação da tipologia construtiva das edificações e suas consequências em relação à salubridade e satisfação dos seus usuários.

A arquitetura tropical vive um impasse diante da perturbação ocasionada pela poluição do ar nos grandes centros urbanos, oriunda principalmente do tráfego veicular, das atividades relacionadas à construção civil e indústrias. Atualmente, com o objetivo de reduzir a quantidade de material particulado dentro dos espaços internos, as estratégias passivas de conforto ambiental perdem lugar diante da prática do fechamento das aberturas do edifício. Tal prática pode apresentar resultados negativos, diante da importância da ação do vento não só em proporcionar conforto térmico, diminuindo a temperatura das superfícies e do corpo do usuário, mas de minimizar as zonas de recirculação do poluente e proporcionar a renovação do ar nos espaços internos (AFLAKI; MAHYUDDIN; MAHMOUD, 2015).

Regiões de clima quente e úmido, geralmente localizadas em baixas latitudes, são caracterizadas por receberem uma radiação solar excessiva. Desta forma, o microclima tanto do ambiente construído quanto do meio urbano é determinado pelo equilíbrio termodinâmico, dentre outros fatores, entre a energia solar absorvida e a energia dissipada. Diante dessa premissa, um dos mecanismos básicos, defendidos pelo conceito do desenho bioclimático é a retirada desse calor por meio da convecção através do incremento da ventilação natural nos espaços públicos e privados (SALKINI; GRECO; LUCENTE, 2017; VICTORIA et al., 2017).

Atualmente o uso de dispositivos de proteção solar nos edifícios residenciais são raros e uma prática muito comum nas últimas décadas, é o fechamento com vidro das aberturas das varandas, descaracterizando um dos principais elementos arquitetônicos em climas subtropicais. Segundo Brandão e Martins (2007, p. 01):

\begin{abstract}
A varanda está relacionada com a sustentabilidade do ambiente construído, pois ao atuar como um fator de sombra e como um grande beiral, ela não apenas se comporta como um elemento de adequação climática da construção, mas também como um recurso de que a própria forma da arquitetura dispõe para proporcionar conforto ambiental ao usuário da edificação em clima tropical quente e úmido, no que diz respeito ao conforto térmico, lumínico e até mesmo acústico, diminuindo a necessidade de soluções artificiais de iluminação e de condicionamento que aumentam o consumo de energia.
\end{abstract}

Um dos exemplos mais emblemáticos em relação ao exposto é o do projeto do condomínio Atlântico Sul no Rio de Janeiro, RJ, erguido em 1979 pelo arquiteto Slomo Wenkert. Premiado internacionalmente, o desenho previa varandas amplas e abertas em que todas teriam uma pequena piscina circular, porém em pouco tempo após sua ocupação, o projeto foi desvirtuado com o fechamento dessas aberturas (TEIXEIRA, 2014). A tendência de fechamento das varandas pelos próprios usuários, sobretudo nos apartamentos de orla marítima foi verificada em outras cidades brasileiras como Recife, Brasília, Vitória e Maceió (TOLEDO; COSTA; BULHÕES, 2010). Tal prática também foi observada em outros países de clima tropical como por exemplo o fechamento ilegal com vidro nas aberturas de varandas no Líbano e sua influência no conforto térmico, como relatado no trabalho de Saleh (2015). 
Os fechamentos das aberturas das varandas com vidros móveis têm dado uma nova imagem à tipologia do edifício residencial multifamiliar brasileiro, fazendo com que fachadas altamente envidraçadas tomem 0 lugar dos espaços de integração com a cidade proporcionado pelas varandas. Além disso, o jogo de volumes compreendido por reentrâncias e saliências acaba sendo substituído por fachadas lisas e, eventualmente, de composição estética duvidosa quando não há uma concordância no uso de uma mesma solução pelos condôminos (JORGE, 2012). Assim, uma desorganização estética da fachada também é observada em algumas situações, em consequência do livre arbítrio do fechamento ou não da varanda pelo morador, decisão muitas vezes que não faz parte do projeto original (Figura 1). Segundo Jorge (2012) percebe-se ainda que o fechamento das varandas resulta, em alguns casos, em uma padronização das soluções de vedação, a partir do uso dos mesmos elementos industrializados, além disso, tal prática é favorecida pela facilidade de intervenção decorrentes, a maior parte das vezes, da ineficiência de controles normativos e pela aceitação imediata dos condôminos, interessados especialmente no acréscimo de área ao ambiente adjacente e pela possibilidade de maior controle das condições climáticas.

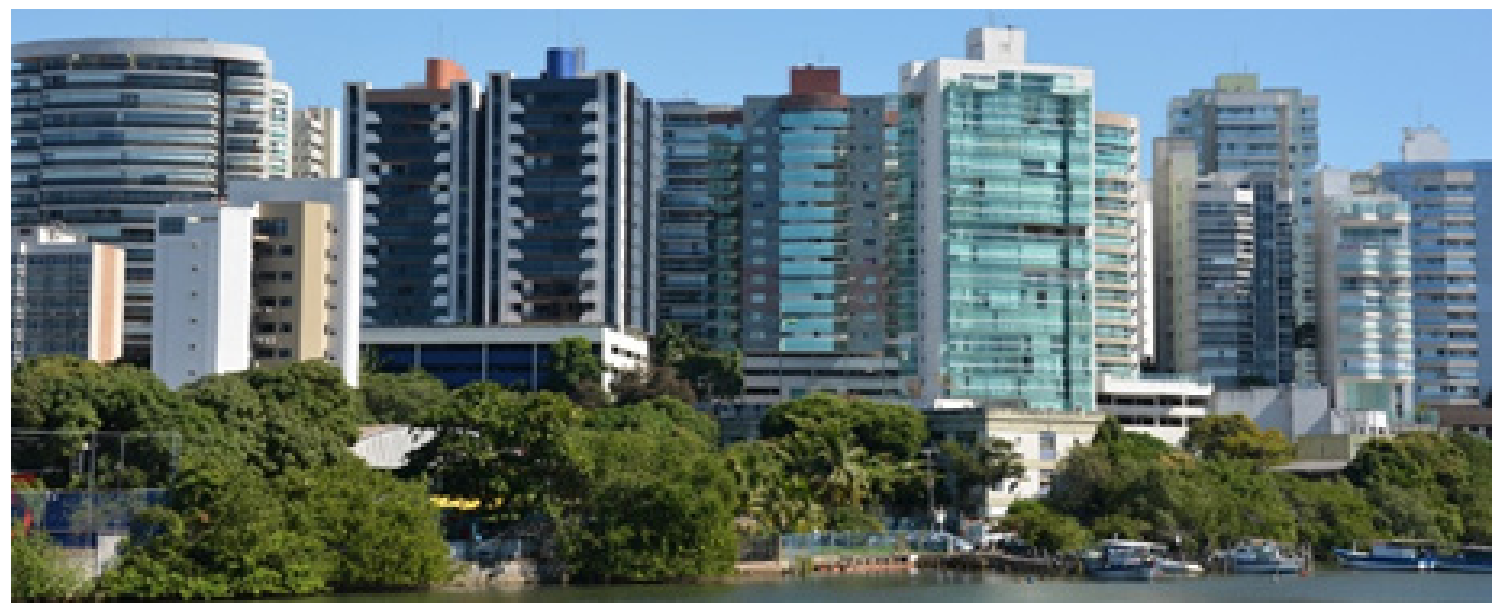

(a)

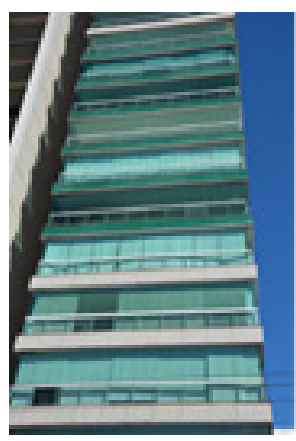

(b)

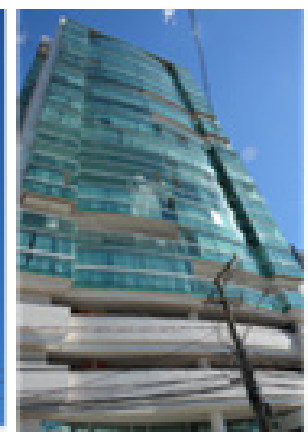

(c)

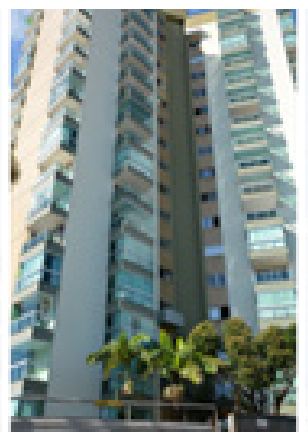

(d)

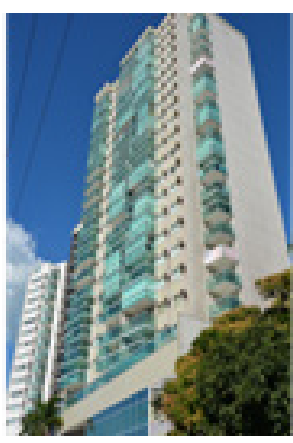

(e)

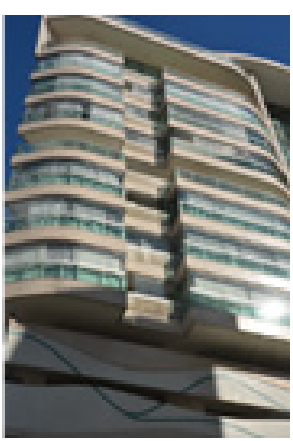

(f)

Figura 1: (a) Vista da baía de Vitória ao fundo o Bairro Praia do Canto. Nota-se a disseminação do fechamento das aberturas da varanda com vidro, alterando a paisagem arquitetônica da cidade. Em (b), (c), (d), (e) e (f) exemplos de edifícios com varandas de diferentes dimensões e formatos com suas aberturas fechadas com vidro em diversos bairros da Grande Vitória, ES

Fonte: Arquivo dos autores 
Além da descaracterização da arquitetura tropical, estudos mostram que os ambientes envidraçados possuem bom desempenho em relação ao conforto térmico apenas em edificações localizadas em regiões de altas latitudes (HILLIAHO; LAHDENSIVU; VINHA, 2015) pois a temperatura do ar dentro das varandas cujas aberturas foram envidraçadas são, quase sem exceção, maiores do que a temperatura do ar externo (HILLIAHO; KOVALAINEN; et al., 2016; HILLIAHO; NORDQUIST; et al., 2016). Além disso, as pesquisas apontam para a redução da taxa de ventilação natural e, consequentemente, uma piora na qualidade do ar interior relacionada ao fechamento do edifício (SANTOS et al., 2011). Ou seja, a prática do fechamento das aberturas da varanda com o intuito de preservar o ambiente interno pode resultar em malefícios a saúde humana, do ponto de vista da qualidade do ar.

A Qualidade do Ar de Interiores - QAI é o resultado da infiltração de poluentes provindos de fontes externas ao edifício somado aos poluentes gerados por fontes internas ao mesmo. Desta forma, admite-se que a taxa de ventilação seja um dos principais fatores que interferem na qualidade do ar interno e da conhecida SED - Síndrome do Edifício Doente (SCHIRMER et al., 2011). Entretanto, pode haver uma discrepância entre a percepção do usuário e a real qualidade do ar dentro das edificações. Silva et al. (2017) realizaram uma avaliação a partir da metodologia APO (Avaliação Pós-Ocupação) em residências localizadas em Luxemburgo com e sem ventilação mecânica. Os resultados mostraram que mais de $80 \%$ dos residentes de ambas as condições de ventilação estavam satisfeitos e a qualidade do ar interna percebida foi julgada "normal", "boa" ou mesmo "muito boa". Entretanto foi detectado que em alguns apartamentos a ventilação mecânica não estava funcionando corretamente e o nível de $\mathrm{CO} 2$ medido excedeu frequentemente o limite crítico, demonstrando que, muitas vezes, a percepção do usuário não corresponde à realidade.

A poluição do ar é conhecida por ter uma série de contaminantes. Dentre esses, as Partículas Totais em Suspensão (PTS), também conhecidas como aerossóis, é um grupo de substâncias ou materiais no estado sólido ou líquido, cujas dimensões são suficientemente pequenas para se manter em suspensão na atmosfera durante algum tempo. A distribuição granulométrica das partículas em relação ao seu tamanho é de grande interesse devido aos efeitos adversos à saúde provocados por essas partículas em certas faixas de tamanho, tais como irritação dos olhos, nariz e garganta; dores de cabeça; tontura e fadiga, contribuindo também para várias doenças respiratórias (ANNESI-MAESANO et al., 2007).

Partículas "muito grandes" - aproximadamente $15 \mu \mathrm{m}$ ou maiores quando inaladas, normalmente não ultrapassam as vias aéreas superiores, sendo removidas ainda no nariz e garganta, e, portanto, não alcançando os pulmões. Partículas "pequenas" - aproximadamente $10 \mu \mathrm{m}$ ou menores -, quando inaladas, têm um maior impacto sobre os seres humanos porque possuem um tempo de vida suficientemente longo, podendo chegar até o sistema respiratório inferior, alcançando assim os alvéolos pulmonares (SEINFELD; PANDIS, 2006). Por sua vez, a fração inalável do Material Particulado (MP), denominado de $\mathrm{MP}_{10}$, pode ser dividido em partículas grossas (entre 2.5 e $10 \mu \mathrm{m}$ ) e finas (menores do que $2.5 \mu \mathrm{m}$, denominado $\mathrm{MP}_{2.5}$ ). Geralmente, as partículas finas possuem altos níveis de toxidade e efeitos adversos a saúde humana (GODISH, 2003). A Organização Mundial da Saúde - OMS estabeleceu como limite a concentração média de $24 \mathrm{~h}$ para qualidade do ar em regiões urbanas de 50 e $25 \mu \mathrm{g} / \mathrm{m} 3$ respectivamente para

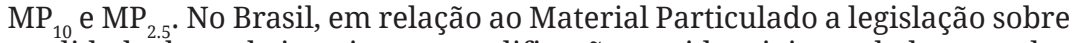
qualidade do ar de interiores em edificações residenciais estabelece o valor limite de $100 \mu \mathrm{g} / \mathrm{m}^{3}$ para PTS estabelecida pela Resolução $\mathrm{N}^{\circ} 9$ da ANVISA (ANVISA, 2003) e reiterada pela NBR 15575/13 que trata do desempenho de edificações habitacionais (ABNT, 2013).

Esse conjunto de fatores já é um indicativo para a necessidade de incremento no desenvolvimento de pesquisas relacionadas à qualidade do ambiente construído em meios urbanos, focados nas condições de conforto e qualidade do ar, tanto pela possibilidade de estudo das variáveis de 
interferência como, também, para garantir a salubridade dos ambientes aos usuários.

\section{A cidade de Vitória - ES}

A cidade de Vitória (LAT $20^{\circ} 19$ '10 "S LONG 40²0’ 16” W), capital do Espírito Santo, localiza-se no sudeste da costa do Brasil, caracterizando-se por um clima tropical litorâneo com temperaturas médias entre $18^{\circ} \mathrm{C}$ e $26^{\circ} \mathrm{C}$, sendo mais elevadas no período do verão, e umidades relativas superiores a $50 \%$. Os ventos predominantes do município são de direção Nordeste (NE) com velocidade entre 2,1-3,6m/s, ocorrendo ainda ventos de direção S-SE e S-SW atribuídos às frentes frias (MATTIUZZI; MARCHIORO, 2012). É a quarta cidade mais populosa do Espírito Santo com 327.801 habitantes (IBGE, 2010), integrando uma área geográfica de grande urbanização denominada Região Metropolitana da Grande Vitória - RMGV.

A localidade possui dois portos que fazem parte do maior complexo portuário do Brasil - Porto de Vitória e Porto do Tubarão -, além de diversas instalações industriais relacionadas à mineração, pelotização, extração de pedra, cimento e alimentos, e tem experimentado um intenso processo de crescimento econômico e urbano nos últimos anos. Parte desse crescimento, se dá pelos grandes projetos industriais implantados na Região Nordeste da cidade desde o início da década de 70 do século passado, e nomeados como o Complexo de Tubarão. De fato, as atividades industriais das duas siderúrgicas de grande porte instaladas nas proximidades do município, associadas à ressuspensão do solo, construção civil e o tráfego de veículos, são as principais fontes de poluição atmosférica locais (SANTOS et al., 2017).

Desta forma a capital do estado do Espírito Santo é constantemente atingida por partículas em suspensão nomeadamente, partículas sedimentáveis. A população local apresenta constantes reclamações acerca do incômodo ocasionado pela presença do denominado "pó preto" no interior de suas residências, sendo frequente o número de protestos e objeções pelos moradores nos noticiários e à Agência Ambiental (COUZEMENCO, 2018; G1, 2018; NOBRES et al., 2018). Além disso, Freitas et al., (2016) avaliou que a cada $10 \mu \mathrm{g} / \mathrm{m} 3$ de acréscimo na concentração de $\mathrm{MP}_{10}$ no ar da cidade de Vitória, foi observado um aumento no risco relativo percentual de hospitalizações por doenças respiratórias totais impactando na morbidade respiratória e cardiovascular de crianças e adultos na cidade.

Melo et al., (2015) destacam em sua pesquisa sobre os fatores determinantes do incômodo causado pela poluição do ar na RMGV, que 86\% dos entrevistados relataram que se sentem incomodados pela poluição do ar na cidade e que mais de $80 \%$ "sempre" e "frequentemente" limpam a casa para retirada do pó. Importante ainda o fato que $76,4 \%$ dos respondentes revelaram "não deixar a janela aberta" por causa da poeira. Tal condição é um incentivador para o fechamento das aberturas das varandas nos edifícios residenciais contribuindo para uma reduzida taxa de renovação do ar e uma piora da qualidade do ar nos ambientes internos.

Embora o código de obras municipal originalmente estabelecesse no seu art.140, $\S 4^{\circ}$ que "As aberturas das varandas não poderão ser fechadas por esquadrias" (PMV, 1998, p.47), no ano de 2006 foi promulgada a Lei ${ }^{\circ}$ 6.801, que alterou o $\S 4^{\circ}$ do artigo 140 ficando este dispositivo com a seguinte redação:

$\S 4^{\circ}$. Fica tolerado o fechamento das varandas desde que os materiais nela empregados garantam plena condição de iluminação, ventilação, permeabilidade ou transparência visual aos compartimentos cujos vãos elas se abrem e sejam instalados sobre o guarda-corpo ou jardineira (PMV, 2006).

Interpretando este dispositivo legal, nota-se que o legislador, ao estabelecer o regramento de fechamento de varandas no Município de Vitória, se preocupou apenas com questões de iluminação e ventilação, 
restringindo-se em disciplinar ou tratar de alguma maneira as demandas que envolvem o desempenho e o conforto ambiental nas edificações. É importante ressaltar ainda que, muitas vezes - como no caso do município de Vitória -, as varandas são projetadas considerando algumas vantagens construtivas propostas pelos Planos Diretores que, de forma correta, incentivam o seu uso, mas que já são idealizadas considerando seu possível fechamento, corrompendo assim tanto o conceito original da função da varanda como seu benefício urbanístico de proporcionar maior integração entre interior e exterior.

Percebe-se que além das inúmeras denúncias e mobilizações da população na busca de soluções para minorar a questão do material particulado em suas residências, também há um movimento para apurar quanto às responsabilidades relacionadas à emissão de partículas poluidoras, em especial do denominado “Pó Preto”. Por outro lado, a pressão ocasionada pelo desconforto dos usuários incentiva a adoção de políticas públicas que levam às mutações nas tipologias edilícias decorrentes do anseio de solucionar o problema - de forma simplista - através das suas vedações. Observa-se também a tendência de utilização de elementos de revestimento visando a fácil limpeza, assim como a concepção de espaços cada vez mais fechados incoerentes com os conceitos bioclimáticos e de salubridade do ambiente de acordo com o clima da região.

\section{OBJETIVO}

O objetivo desta pesquisa foi avaliar a qualidade ambiental e a percepção do morador de apartamentos na cidade de Vitória - ES, com e sem fechamento em vidros móveis nas aberturas de suas varandas.

\section{METODOLOGIA}

A metodologia deste trabalho adotou como recorte temporal e territorial o período do verão entre os meses de janeiro e fevereiro de 2017 em um condomínio residencial no Bairro Jardim Camburi em Vitória, ES, e foi dividida em duas etapas principais: a) realização de um estudo transversal, descritivo, através da aplicação de questionários padronizados de avaliação ambiental e percepção do usuário; b) realização de um experimento de campo através de medições internas das condições ambientais (temperatura do ar e umidade relativa do ar) da varanda e sala de estar em dois apartamentos de orientações distintas, e monitoramento da qualidade do ar (Material Particulado) na varanda de um desses apartamentos orientado à nordeste. $\mathrm{O}$ apartamento a nordeste, por estar orientado na direção do vento predominante da cidade, foi monitorado alternando as condições de fechamento dos vidros móveis, almejando verificar a influência das circunstâncias de operação desse dispositivo no conforto térmico e na qualidade do ar do ambiente.

\section{o Condomínio residencial de estudo}

O condomínio residencial selecionado para estudo localiza-se em um terreno de $15.408 \mathrm{~m}^{2}$ no Bairro Jardim Camburi em Vitória, ES, selecionado por estar próximo ao principal polo siderúrgico industrial da região bem como de vias de grande fluxo veicular. Trata-se de um condomínio composto por cinco edifícios multifamiliares e ampla área de lazer destinados à classe média e alta. Cada torre possui vinte andares, com variação de quatro a seis unidades habitacionais por pavimento, totalizando em 396 apartamentos em todo o conjunto. As unidades variam de 3 a 4 quartos, sendo que todas possuem uma varanda anexa à sala de estar e quartos. Mesmo tendo sido inaugurado em 2011, ainda possui cerca de 100 apartamentos à venda.

Trata-se de uma tipologia arquitetônica residencial representativa da região estudada e de demais cidades brasileiras. As edificações são compostas 
por estruturas de concreto; alvenarias de tijolos cerâmicos furados e blocos de concreto vibrado revestidos de argamassa; e janelas e guarda-corpo de varandas em vidro laminando e esquadrias de alumínio. Os apartamentos monitorados se localizam no $18^{\circ}$ andar da Torre D à noroeste e no $10^{\circ}$ andar da Torre $\mathrm{E}$ à nordeste, sendo que ambos tiveram suas aberturas das varandas fechadas em vidros móveis do tipo incolor temperado de $8 \mathrm{~mm}$ (Figura 2). Internamente à varanda do apartamento da Torre $\mathrm{D}$, foram instaladas cortinas de tecido do tipo blackout. Os apartamentos são compostos por três quartos, possuindo aproximadamente $135 \mathrm{~m}^{2}$ de área total, sendo a área da varanda e da sala de 18,60 e $36,67 \mathrm{~m}^{2}$ respectivamente. A sala e a varanda são divididas por uma parede de alvenaria com uma porta de vidro de correr que faz o acesso entre esses ambientes.

O período de monitoramento foi de 4 (quatro) semanas. Com o objetivo de se avaliar a influência do modo de operação dos vidros móveis no conforto térmico e na qualidade do ar, alternou-se as condições do fechamento deste dispositivo no apartamento da Torre E. Para este foram definidas as seguintes situações: i) duas semanas mantendo uma pequena abertura em duas folhas resultando em $96 \%$ do fechamento total e ii) duas semanas mantendo as folhas totalmente abertas, recolhidas às duas laterais. Os vidros móveis foram fechados ou abertos sempre às sextas-feiras. Já o apartamento da Torre D permaneceu durante as quatro semanas de monitoramento com a condição dos vidros móveis sempre fechados, também com uma abertura mínima de uma de suas partes.

Uma vez que, é comum na região a maior parte dos habitantes utilizarem os vidros móveis da varanda frequentemente com uma parcela aberta - principalmente, em função do desconforto térmico ocasionado quando os vidros se encontram totalmente fechados; optou-se por manter a condição de uma abertura mínima na condição de monitoramento fechado dos apartamentos, aproximando desta forma, os resultados das medições com as condições reais de operação desse dispositivo.

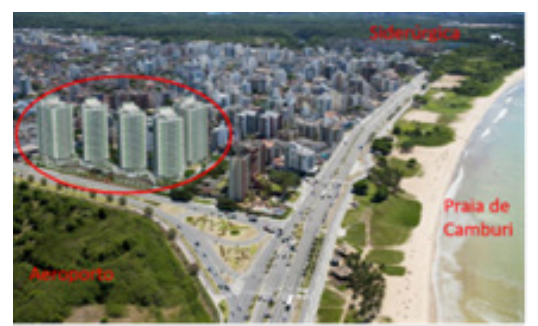

(a)

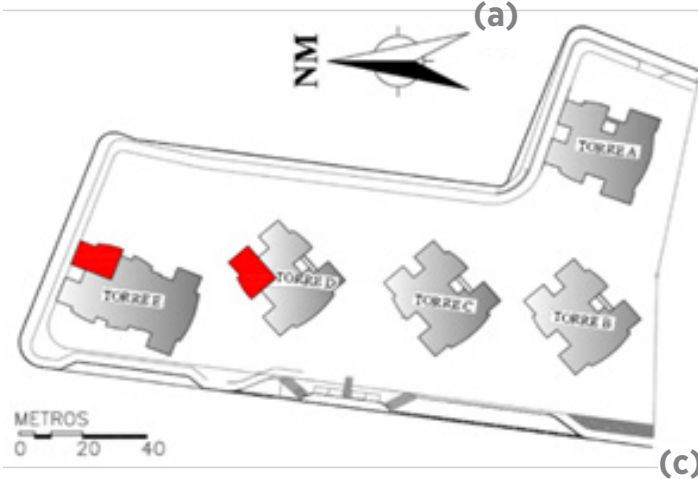

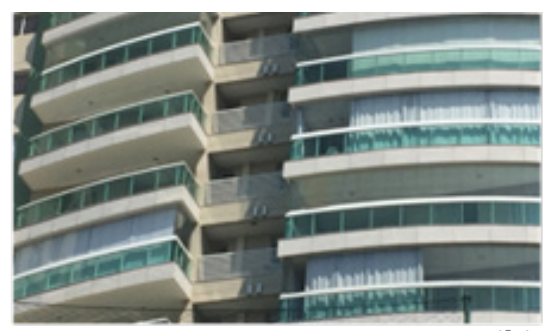

(b)

Figura 2: (a) Bairro Jardim Camburi com destaque para o residencial de estudo. (b) Tipologia das varandas envidraçadas. (c) Implantação do condomínio com destaque para o posicionamento dos apartamentos monitorados. (d) Vista interna do fechamento em vidro móvel utilizado na varanda do apartamento da Torre E

Fonte: (a) Adaptado de Galwan (2018) e (b, c, d) Arquivo dos autores 


\section{Questionários}

O questionário para avaliação da percepção do morador em relação ao conforto térmico e à qualidade do ar levando em conta a presença ou não do fechamento das aberturas das varandas com vidros móveis, foi elaborado seguindo as recomendações da EN ISO 28802:2012 (THE EUROPEAN STANDARDIZATION, 2012) bem como a utilização de algumas perguntas já aplicadas por Melo et al. (2015) em seu estudo sobre os fatores determinantes do incômodo causado pela poluição do ar. A aplicação dos questionários foi submetida na plataforma Brasil (http://plataformabrasil.saude.gov. br) e aprovado pelo Comitê de Ética em Pesquisa com Seres Humanos da Universidade Federal do Espírito Santo (CAAE $n^{\circ}$ 64950817.0.0000.5542) assim como autorizada pelo administrador geral do condomínio. A pesquisa foi apresentada durante uma reunião de condomínio com os moradores e síndicos de cada torre onde foram distribuídos os formulários e sanadas as eventuais dúvidas. Foi convidado a participar do estudo um morador representante de cada unidade habitacional, maior de 18 anos. Informações sobre os objetivos da pesquisa, confidencialidade dos resultados e garantia de privacidade foram fornecidas. Cada participante assinou o termo de consentimento livre e esclarecido e, posteriormente, respondeu aos questionários. Para o cálculo do tamanho mínimo da amostra a ser atendida considerando uma população finita, utilizou-se a Equação 1 (MIOT, 2011) com um intervalo de confiança de $90 \%$ e uma margem de erro de $10 \%$.

$$
n=\frac{N \times p \times q \times(Z \propto / 2)^{2}}{(N-1) \times(E)^{2}+p \times q \times(Z \propto / 2)^{2}}
$$

$n=$ tamanho da amostra; $Z_{\alpha 2 / 2} / 2=1,645$ valor crítico utilizado para o grau de confiança estipulado de 90\%; $E=$ margem de erro; $N$ = tamanho da população (finita); $p$ = proporção de elementos com característica estudada (adotou-se 0,5 uma vez que essa proporção é desconhecida); $q=(1-p)$.

O questionário foi elaborado em três seções. A primeira parte aborda perguntas relativas ao perfil do respondente e caracterização de fechamento ou não da abertura da varanda, bem como os motivos que levaram a essa ação, as condições de utilização do fechamento, a frequência e uso do espaço. A segunda parte investiga a percepção do morador em relação ao conforto térmico nas estações do verão e inverno e o índice de satisfação com esse quesito. A terceira parte é sobre a percepção em relação a qualidade do ar, abordando questões sobre como o usuário classifica a importância e o incomodo na região em que mora e na área da sua varanda, e sua percepção em relação à provável fonte de poluição e suas principais consequências à saúde.

\section{Experimento de campo}

Para o monitoramento das condições ambientais internas dos apartamentos selecionados, foram utilizados equipamentos armazenadores de dados (data loggers) do tipo HOBO, modelo U12-013, para medir e armazenar dados de temperatura do ar e umidade do ar. Os valores armazenados foram transferidos para um computador através do programa HOBOware (Software for HOBO U-Series Data Loggers \& Devices), versão 2.7, para Windows. Foram realizadas medições na varanda e sala de estar simultaneamente nos dois apartamentos da Torre D e E, utilizando um total de quatro HOBOS. Cada apartamento teve dois equipamentos instalados, sendo um na varanda e outro na sala de estar. Estes foram posicionados aproximadamente a $1,10 \mathrm{~m}$ do piso (BARBOSA; WEILLER; LAMBERTS, 2007) e devidamente abrigados (Figura 3a) seguindo as recomendações da ISO 7726:1998 (ISO, 1998). Cada HOBO foi programado para registrar as informações em intervalos de 1 minuto. Temperatura do ar e umidade 
relativa do ar exterior foram obtidos através da Rede de Estações Meteorológicas Automáticas do Instituto Nacional de Meteorologia - INMET, da Estação automática localizada na Universidade Federal do Espírito Santo no bairro Goiabeiras, localizada a aproximadamente $4 \mathrm{Km}$ da região de estudo (INMET, 2017). Foram registradas as médias horárias ao longo de 24 $\mathrm{h}$, simultâneas às semanas experimentais realizadas, a fim de possibilitar a comparação dos dados internos e externos.

A qualidade do ar interna foi avaliada pelo monitoramento da concentração do material particulado na varanda do apartamento do $10^{\circ}$ andar da Torre E, por este se localizar a nordeste, direção do vento predominante na cidade no verão. Para caracterizar e quantificar a concentração numérica e de massa do material particulado foi utilizado um Espectrômetro Portátil de Aerosol - modelo Dust monitor 1.109 de fabricação da GRIMM TECHNOLOGIES, INC, Germany, capaz de detectar 31 faixas de tamanhos de partículas, caracterizando-as em intervalos de classes de $0,25 \mu \mathrm{m}$ a $>32 \mu \mathrm{m}$. Este espectrômetro trabalha com fluxo constante de ar controlado por uma bomba a $1,2 \mathrm{~L} / \mathrm{min} \pm 5 \%$ previamente calibrada. $\mathrm{O}$ equipamento foi colocado dentro de um abrigo de fabricação da Grimm Tecnologies, Germany, e juntamente ao mesmo foi deixado um diário de anotações para registro pelo morador de possíveis atividades no ambiente (Figura $3 \mathrm{~b}$ e 3c). Externamente foram utilizados os dados de $\mathrm{PM}_{10}$ (partículas com diâmetro menor do que $10 \mu \mathrm{m}$ ) disponibilizadas pelo Instituto Estadual de Meio Ambiente - IEMA coletados pela Estação de Jardim Camburi localizada a 1,2 Km da região de estudo (IEMA, 2018). Por problemas na rede de monitoramento da qualidade do ar os dados do dia 07/02 ao dia 13/02 não estavam disponíveis.

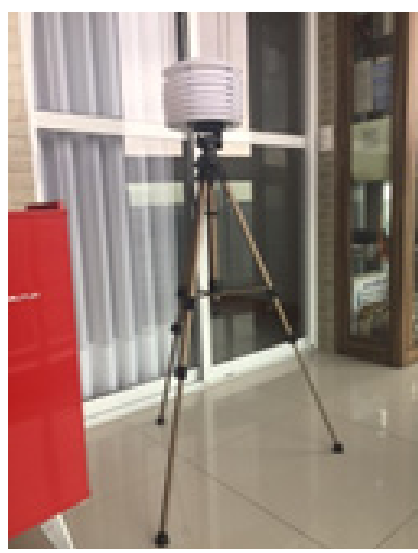

(a)

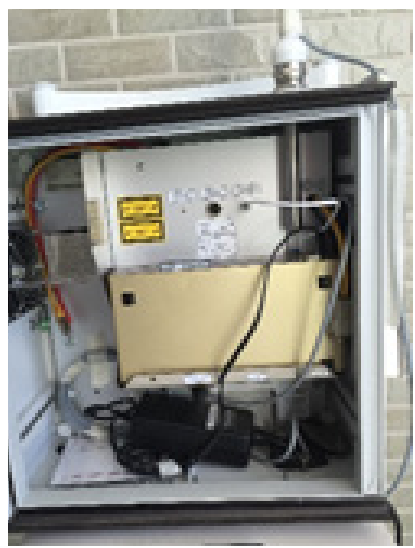

(b)

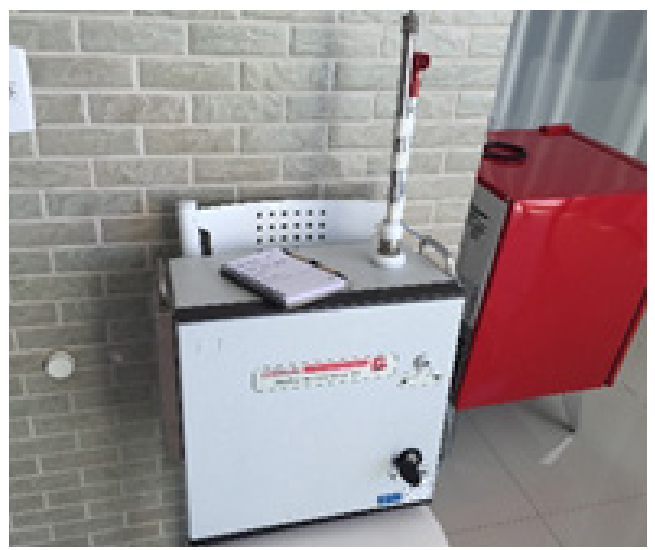

(c)

Figura 3: Condição de exposição dos equipamentos na varanda de um dos apartamentos monitorados (a) HOBO localizado a 1,10 m de altura e devidamente abrigado, (b) Espectrômetro Portátil de Aerosol com o abrigo do equipamento aberto, (c) Espectrômetro Portátil de Aerosol com o abrigo do equipamento fechado

Fonte: Arquivo dos autores

\section{RESULTADOS E DISCUSSÕES}

Considerando a metodologia adotada, os resultados foram avaliados a partir dos dois instrumentos adotados: os questionários (percepção do usuário) e as medições (avaliação do conforto térmico e da qualidade do ar). 


\section{Experimento de campo}

Foram respondidos 92 questionários por usuários de todas as torres do condomínio, sendo a maior parte dos participantes proprietários do imóvel $(94,6 \%)$ e entre $30-40$ anos de idade $(51,4 \%)$. A porcentagem entre homens $(48,9 \%)$ e mulheres (51,1\%) respondentes ficou equilibrada, destacando-se ainda que cada apartamento possui, em média, de 3 a 4 moradores. Observa-se que $94,6 \%$ dos respondentes fecharam a abertura de suas varandas com vidros móveis e que $80 \%$ dos moradores que ainda não fecharam tem intenção de fechar. Os resultados dos questionários estão sintetizados na Tabela 1.

\begin{tabular}{lc}
\hline DADOS GERAIS & \\
\hline - Idade & \\
Menos de 30 anos & $3(3,3 \%)$ \\
$30-40$ anos & $47(51,1 \%)$ \\
$40-50$ anos & $30(32,6 \%)$ \\
$50-60$ anos & $10(10,9 \%)$ \\
Acima de 60 anos & $2(2,2 \%)$ \\
\hline - Sexo & \\
Feminino & $47(51,1 \%)$ \\
Masculino & \\
& $45(48,9 \%)$ \\
\hline - Propriedade do imóvel & \\
Inquilino & $5(5,4 \%)$ \\
Proprietário & $87(94,6 \%)$ \\
\hline - Quantidade de moradores por unidade \\
1 & $1(1,1 \%)$ \\
2 & $18(19,6 \%)$ \\
3 & $27(29,3 \%)$ \\
4 & $35(38,0 \%)$ \\
5 & $9(9,8 \%)$ \\
Mais de 5 & $2(2,2 \%)$ \\
\hline
\end{tabular}

\begin{tabular}{lc}
\hline LOCALIZAÇĀO APARTAMENTO (TORRE) \\
\hline A & $22(23,9 \%)$ \\
B & $14(15,2 \%)$ \\
C & $16(17,4 \%)$ \\
D & $10(10,9 \%)$ \\
E & $30(32,6 \%)$ \\
\hline
\end{tabular}

\begin{tabular}{lc}
\hline \multicolumn{2}{l}{ CARACTERIZAÇÃO DA VARANDA } \\
\hline $\begin{array}{l}\text { - Frequência de utilização da } \\
\text { varanda }\end{array}$ \\
Menos que 2 vezes por semana & $20(21,7 \%)$ \\
De 2 a 3 vezes por semana & $22(23,9 \%)$ \\
Mais de 4 vezes por semana & $48(52,2 \%)$ \\
Não é utilizada & $2(2,2 \%)$ \\
\hline - Varanda possui fechamento com vidro? \\
Não & $5(5,4 \%)$ \\
Sim & $87(94,6 \%)$ \\
\hline - Tem intenção de fechá-la? (n=5) & \\
Não & $1(20,0 \%)$ \\
Sim & $4(80,0 \%)$ \\
\hline
\end{tabular}

Tabela 1: Dados gerais dos participantes e caracterização da varanda $(n=92)$

Fonte: Arquivo dos autores

A maioria dos residentes atribui a poeira $(82,6 \%)$ seguido de fatores climáticos - sol, vento e chuva $(69,6 \%)$ como os principais motivos para o fechamento das varandas (Gráfico 1). Esse resultado demonstra ser o incômodo ocasionado pela poluição do ar como o principal motivo para o fechamento das aberturas de suas habitações, reiterando o resultado encontrado também por Melo et al. (2015). Desta forma, pode-se inferir que tal fato contribuiu na alteração da tipologia construtiva das edificações multifamiliares residenciais do município, uma vez que, mesmo que não prevista no projeto original, a utilização dos vidros móveis nas varandas é um produto desejável na ocupação efetiva da unidade habitacional.

O espaço da varanda não perdeu seu uso, relatado por $52,2 \%$ dos respondentes, como um local utilizado mais de 4 vezes por semana. Como pode ser visto no Gráfico 2, os usos mais frequentes têm relação com a utilização do local como espaço gourmet (47,8\%), extensão da sala de estar $(30,4 \%)$ e estar $(31,5 \%)$. 


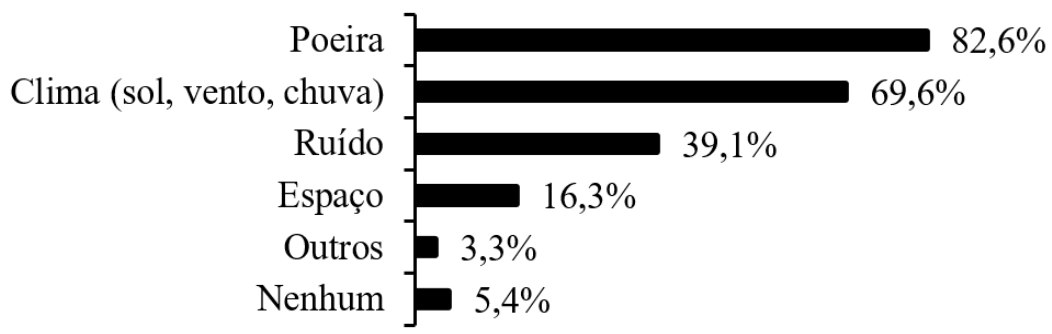

Gráfico 1: Resultados das respostas em relação à pergunta "Qual(s) foi o motivo do fechamento da varanda?"

Fonte: Dos autores

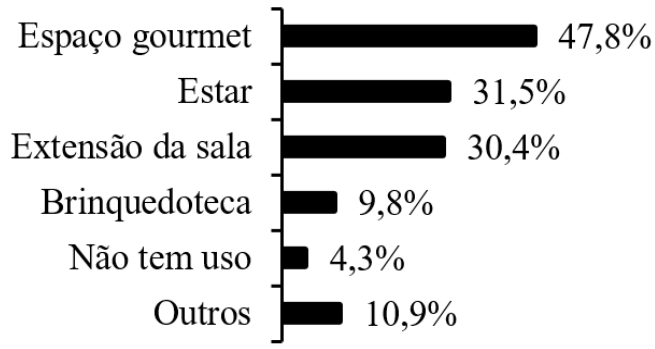

(a)

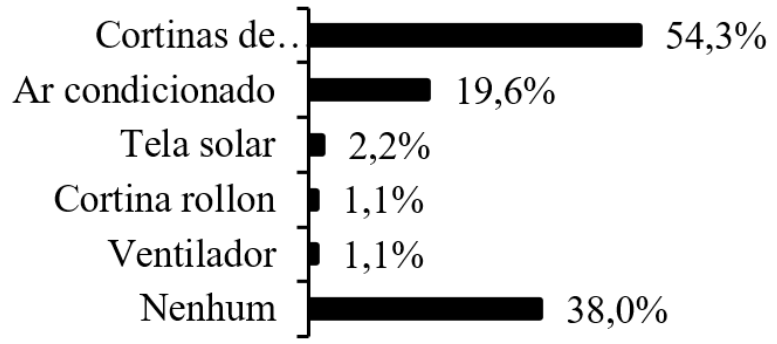

(b)

Gráfico 2: Resultados das respostas (a) "Como a sua varanda é normalmente utilizada?" e (b) "Você utiliza algum recurso adicional na sua varanda para melhoria do conforto térmico?"

Fonte: Dos autores

Toledo, Costa e Bulhões (2010) verificaram em seu estudo sobre os novos usos das varandas na orla de Maceió, que após o fechamento os usuários passaram a utilizá-la com maior frequência, mantendo seu uso original ou modificando. Entretanto, nota-se uma nova e preocupante tendência verificada pelo presente trabalho: a climatização artificial neste ambiente. Quando indagados com a pergunta "Você utiliza algum recurso adicional na sua varanda para melhoria do conforto térmico?”, uma parcela significativa dos moradores $(19,6 \%)$ respondeu que faz uso do ar condicionado no local, atrás apenas da resposta de utilização de cortinas de tecido ou do tipo blackout (54,3\%).

Pode-se dizer que o fechamento da varanda colabora em uma maior frequência no uso do espaço, protegendo das adversidades climáticas inerentes a edifícios altos, como vento e chuva. Entretanto, por se tratar de um clima tropical quente e úmido, o uso de vidros no fechamento das aberturas da varanda aumenta a temperatura do ar no espaço interior, fazendo com que seus usuários recorram ao condicionamento do ar através de equipamento elétrico, aumentando o consumo energético e contradizendo os preceitos de uma arquitetura mais sustentável.

Em relação a condição de abertura dos vidros móveis da varanda, à percepção do usuário acerca do conforto térmico nas estações do verão e inverno na varanda e o índice de satisfação com esse quesito, nota-se que o morador percebe a temperatura do ar como "quente" no verão, sendo verificado na maior parte dos resultados relatos de "muito quente". A 
sensação de "frio” aparece apenas na estação do inverno sendo predominante nesta a resposta de sensação "neutra”. No entanto, é curioso observar que mesmo com o fechamento da abertura da varanda, a sensação de ventilação natural é registrada em ambas as estações. Tal fato talvez possa ser explicado em função da maior parte dos respondentes usualmente manter o fechamento dos vidros móveis na condição "meio aberto". Isso demonstra que embora a maioria dos moradores instale os vidros móveis nas aberturas de suas varandas, provavelmente devido ao desconforto térmico estes não são utilizados sempre fechadas (Gráfico 3).

(a)

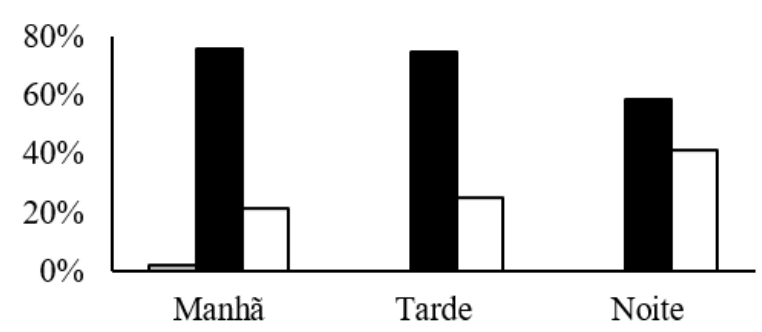

口Totalmente aberta $\square$ Meio aberta $\square$ Totalmente fechada

(b)

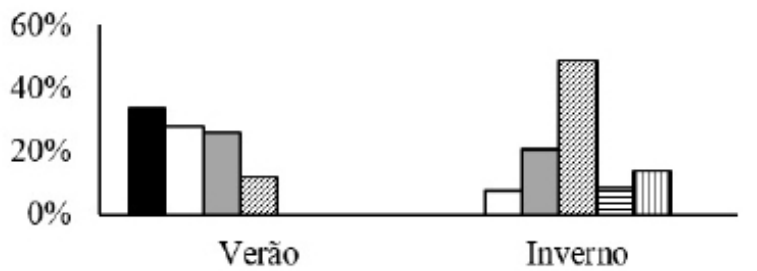

- Muito quente

$\square$ Moderadamente quente

口Levemente quente

Neutra

日Frio

৫Moderadamente frio

Muito frio (c)

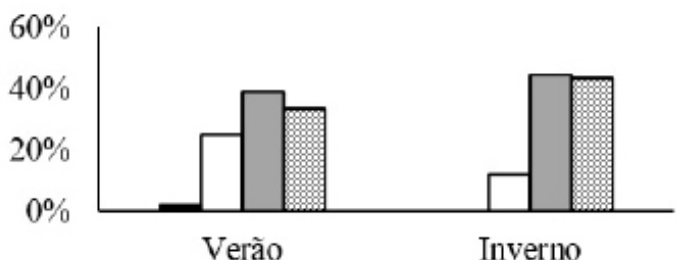

- Sem ventilação

口Levemente ventilada

aVentilada

Muito Ventilada

Gráfico 3: Resultados das respostas (a) "Como é usual manter o fechamento da vidro na varanda?"; (b) "Em relação a temperatura do ar como você se sente na sua varanda nas seguintes estações - verão e inverno?”; e (c) Em relação a ventilação natural como você a percebe na sua varanda nas seguintes estações - verão e inverno?"

Fonte: Dos autores

De uma forma geral, a maior parte dos usuários (73\%) classifica-se como "satisfeito" em relação ao conforto térmico da sua varanda em contrapartida a $27 \%$ que responderam que se sentem "insatisfeito" em relação a esse quesito. Pode-se atribuir esse resultado à possibilidade de operacionalização das folhas de vedação de vidro utilizadas no fechamento, fazendo com que o próprio usuário controle a condição de abertura ou recorra a recursos adicionais para melhoria do conforto térmico.

A terceira parte dos resultados do questionário que diz respeito à percepção da qualidade do ar na região de estudo, mostra que a maioria dos respondentes do condomínio avaliam a qualidade do ar no seu bairro como "péssima" ou "ruim", bem como 92,4\% dos participantes se sentem incomodados com a poluição do ar na região. Tal fato reforça o problema da cidade em relação aos níveis percebidos pela população do material particulado. Os resultados em relação a percepção da qualidade do ar na área da varanda do apartamento, são levemente mais positivos, provavelmente pela barreira construída que se torna a edificação e seus fechamentos em relação à entrada de poluentes. A maior parte dos moradores relatam 
a qualidade do ar em sua varanda como "regular" e "ruim", e 91,2\% dos respondentes se sentem incomodados com a poluição atmosférica no ambiente (Gráfico 4).

(a)

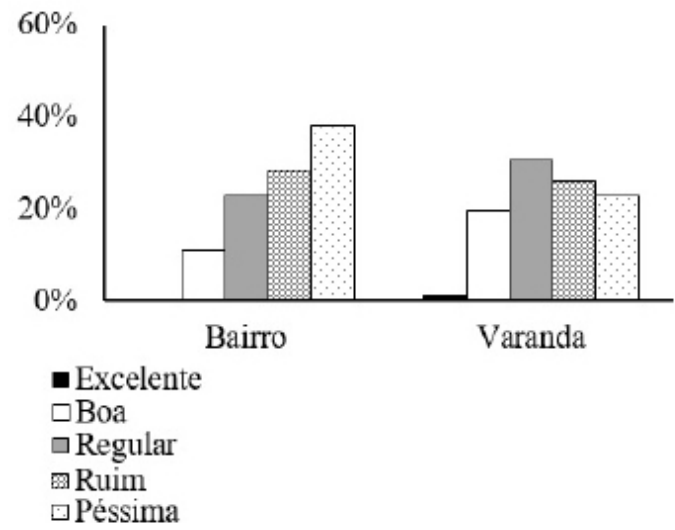

(b)

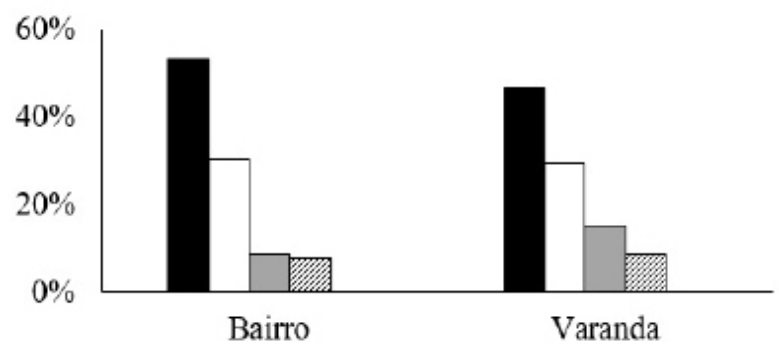

Extremamente incomodado

$\square$ Muito incomodado

$\square$ Moderadamamente incomodado

Q Pouco incomodado

$\checkmark$ Nada incomodado

Gráfico 4: Resultados das respostas (a) "Como você avalia a qualidade do ar no bairro em que você reside? E na varanda do seu apartamento?" e (b) "Você se sente incomodado com a poluição no seu bairro? E na sua varanda?"

Fonte: Dos autores

É de suma importância relatar que 97,8\% dos participantes percebem a interferência na qualidade do ar do seu apartamento através da presença da poeira, e, portanto, essa é a principal causa do incômodo registrado pelos moradores. Embora a maior parte dos apartamentos possuam o fechamento das aberturas das varandas e declarem que o principal motivo dessa ação seja o incômodo ocasionado pelo pó, observa-se que tal atributo não resolve significativamente o problema da melhoria da qualidade do ar na habitação. Os resultados mostram que $52,2 \%$ dos moradores precisam fazer a limpeza do apartamento todo dia e $25 \%$ dos participantes mais de 3 vezes por semana. Esses valores reforçam a busca pela população citadina por soluções arquitetônicas mitigadoras do problema ambiental (Gráfico 5).

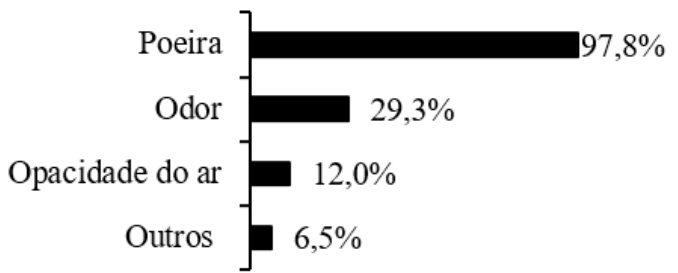

(a)

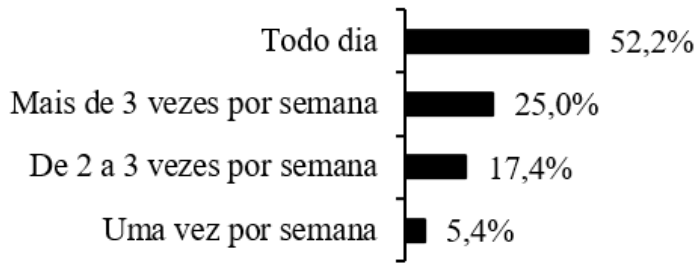

(b)

Gráfico 5: Resultados das respostas (a) "Em qual dessas situações você percebe a qualidade do ar no seu apartamento?”; e (b) "Em relação as consequências da qualidade do ar qual a frequência de limpeza do apartamento para retirada de poeira?"

Fonte: Dos autores

Quando indagados sobre as principais fontes externas e internas de poluição que acreditam que influenciam na qualidade do ar do seu apartamento (Gráfico 6), os moradores relataram as mesmas fontes externas registradas em medições realizadas por SANTOS et al. (2017), ou seja, a industrial, veicular e construção civil. Como fontes internas, foram citadas as atividades de cozinhar, limpar a casa e uso de cosméticos, sendo essas fontes de grande influência na poluição do ar em ambientes internos, relatadas pela literatura (PAGEL et al., 2017). 


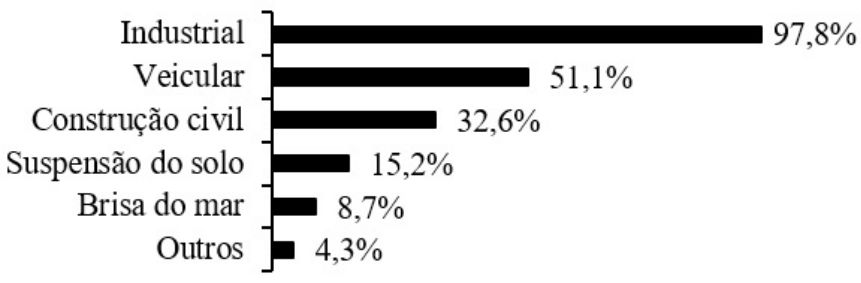

(a)

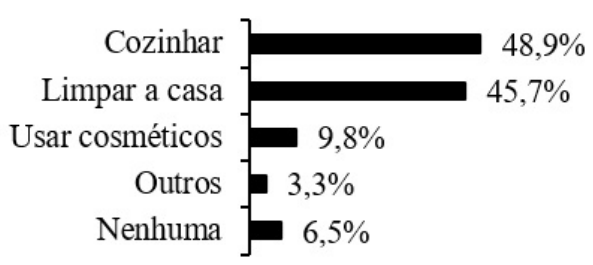

(b)

Gráfico 6: Resultados das respostas "Qual ou quais as principais de poluição que você acredita que influenciam na qualidade do ar do seu apartamento? (a) externa e (b) internas?"

Fonte: Dos autores

As últimas perguntas indagam se os participantes já tiveram problemas de saúde em decorrência da poeira e quais seriam esses. Do total de respondentes, 43,5\% declarou que "as vezes", 25\% declarou que "sempre" e $31,5 \%$ declarou que "nunca” teve problemas de saúde em relação à poeira. Dos que declararam que já apresentaram problemas de saúde, 84,1\% dos casos relatados são de rinite, sinusite e alergia (Gráfico 7). Estudos prévios na literatura existente mostraram que há uma correlação positiva entre a concentração de poluentes aéreos, principalmente de Material Particulado, com sintomas de rinite alérgica - espirro, coriza e obstrução nasal -, mesmo com níveis de poluentes menores que os permitidos pela legislação (NICOLUSSI et al., 2014).

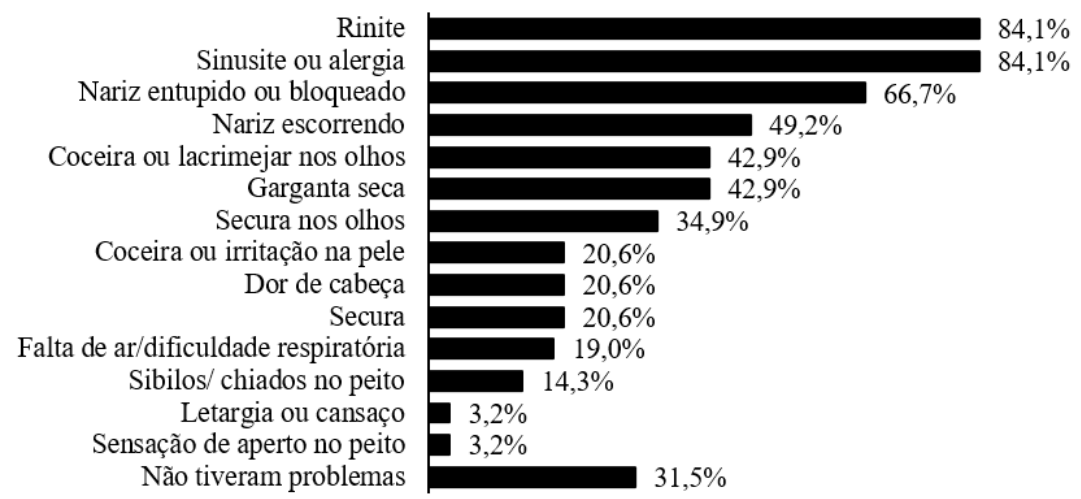

Gráfico 7: Resultados das respostas "Se você já teve problemas de saúde em decorrência da poeira, qual ou quais dos problemas abaixo você já teve em função da presença da poeira?"

Fonte: Dos autores

\section{Avaliação do conforto térmico e da qualidade do ar}

Para cálculo da faixa de conforto em ambientes naturalmente ventilados foi utilizada a metodologia de conforto adaptativo que adota a variação da média mensal da temperatura do ar externa e a porcentagem de aceitabilidade para a determinação dos valores máximos e mínimos da temperatura de conforto, conforme sugerido pela ASHRAE 55 (ASHRAE STANDARD, 2013). Candido e Dear (2012, p.81) defendem que "o modelo adaptativo de conforto térmico oferece uma nova abordagem para edifícios naturalmente ventilados ao estabelecer que as flutuações de temperatura podem ser entendidas como aceitável para os seus ocupantes”. Esta abordagem reforça a adoção de espaços naturalmente ventilados como uma das estratégias para a conservação de recursos, contribuindo para a construção de edificações cada vez mais integradas ao contexto bioclimático em que estão inseridas. A temperatura do ar média mensal externa obtida pela Estação do INMET foi inserida no gráfico de conforto adaptativo, obtendo-se o intervalo de temperatura de conforto para o período em questão, 
considerando $90 \%$ de aceitabilidade (Tabela 2). A escolha do percentual de aceitabilidade do usuário de $90 \%$ é justificada para a cidade de Vitória, cuja a ação do vento predominante interfere significativamente na facilidade de adaptação pelo usuário às variações de temperatura (NICO-RODRIGUES et al., 2015). Observa-se que a ASHRAE 55 também propõe o uso do percentual de $90 \%$ como condicionante para a obtenção de uma faixa mais ampla de conforto térmico.

\begin{tabular}{|c|c|c|c|}
\hline Período & $\begin{array}{l}\text { Temperatura médla mensal } \\
\text { do ar externo }\left({ }^{\circ} \mathrm{C}\right)\end{array}$ & $\begin{array}{l}\text { Temperatura neutra }\left({ }^{\circ} \mathrm{C}\right) \\
\text { Tn=0,31(Te) }+17,8\end{array}$ & 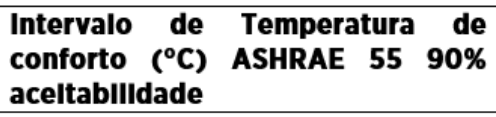 \\
\hline $07 / 01$ a $03 / 02$ & 27,57 & 26,34 & $23,84-28,84$ \\
\hline
\end{tabular}

Tabela 2: Valores de temperatura média mensal do ar externo do período e temperatura de conforto

Fonte: Dos autores

Analisando as médias de $24 \mathrm{~h}$ da temperatura do ar percebe-se que a temperatura externa é menor do que a interna tanto nas salas quanto nas varandas na maior parte dos dias (Gráfico 8). Em relação à média da temperatura do ar calculadas nas salas de estar, percebe-se uma similaridade entre as médias de $24 \mathrm{~h}$ nos dois apartamentos, com exceção dos períodos em que os vidros móveis da varanda da Torre E estavam abertos, o que fez com que as médias de temperatura do ar na sala dessa Torre fossem menores em até $0,5^{\circ} \mathrm{C}$ na maior parte dos dias, em relação aos valores da sala da Torre D. É importante ressaltar que mesmo a cortina de tecido sendo relativamente eficiente na atenuação da temperatura interna, tanto da varanda quanto da sala, a presença dos vidros móveis fechados elevaram a temperatura do ar de todos os ambientes em relação a temperatura do ar externo registrada no período analisado.

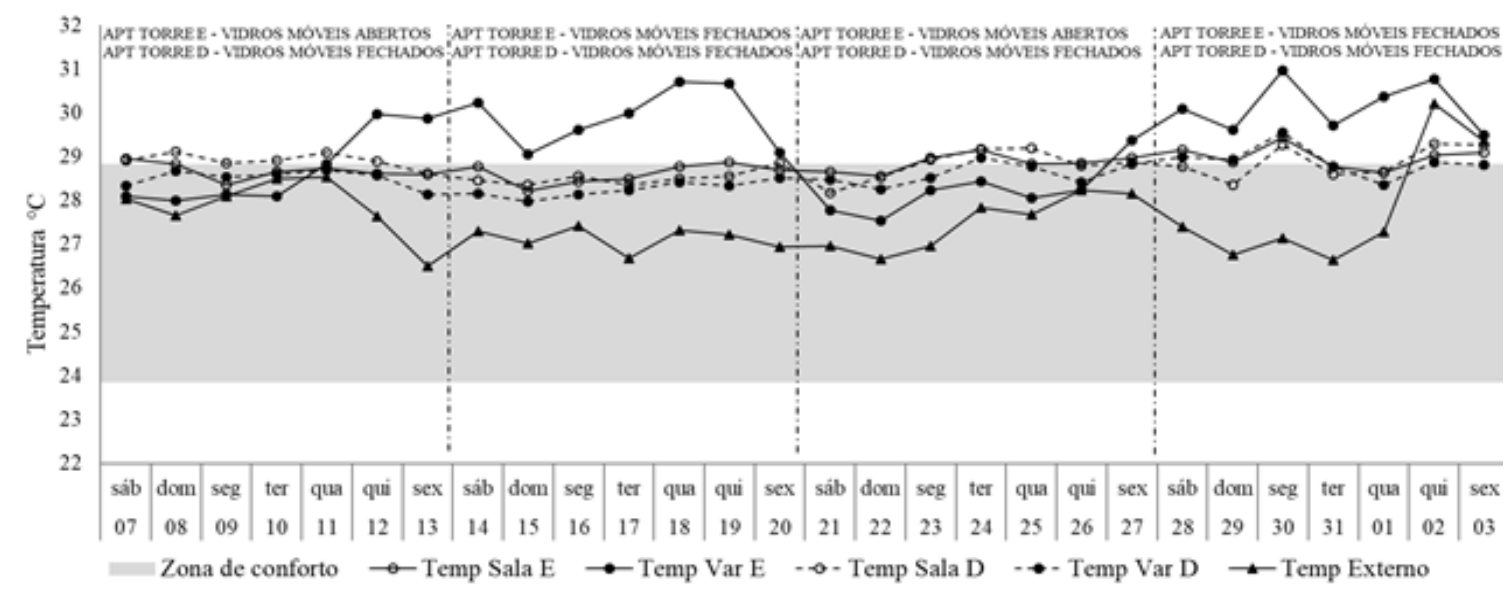

Gráfico 8: Médias diárias de temperatura do ar monitoradas nas salas e varandas da Torre E e da Torre D

Fonte: Dos autores

Especificamente na Torre E é interessante observar que durante as duas semanas em que os vidros móveis da varanda estavam totalmente abertos, a média de temperatura do ar diária nessa varanda aproximou-se da média da temperatura do ar registrada externamente, com valores menores aos registrados na varanda da Torre D, cujo monitoramentos foram 
feitos sempre com os vidros fechados. Além da condição dos vidros móveis abertos, a orientação da varanda da Torre E, predominantemente nordeste, pode ter contribuído nesse resultado por ser mais favorável termicamente do que a varanda da Torre D (predominantemente noroeste). Analisando os períodos em que os vidros móveis da Torre E estavam fechados, nota-se uma variação de até $3,83^{\circ} \mathrm{C}$ a mais na média diária em relação à temperatura do ar externo, ficando a mesma nestes períodos bem acima da zona de conforto recomendada pela ASHRAE. O Gráfico 9 mostra as temperaturas operativas horárias resultantes das medições da campanha experimental na varanda da Torre E, na condição dos vidros móveis abertos e fechados, distinguindo as flutuações dos valores durante o dia e a noite, plotados sobre o modelo da ASHRAE 55. É perceptível a gama de temperaturas fora da faixa aceitável para os ocupantes durante o dia, principalmente, na condição dos vidros móveis fechados na varanda.
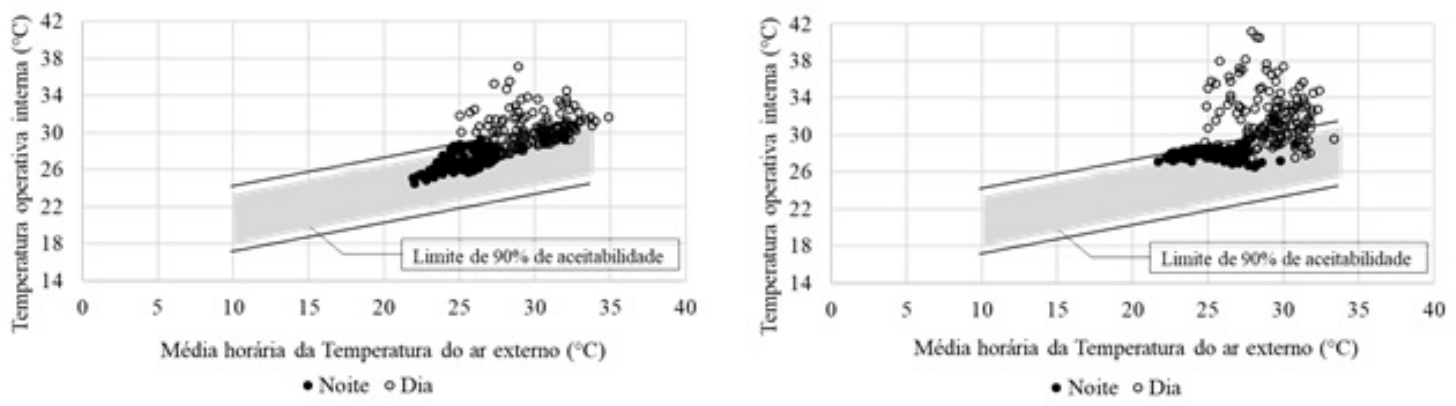

- Noite oDia

Gráfico 9: Temperaturas operativas horárias da varanda da Torre E plotadas sobre o modelo da ASHRAE 55 na condição dos vidros móveis (a) abertos e (b) fechados

Fonte: Dos autores (2018) adaptado de ASHRAE 55 (ASHRAE STANDARD, 2013)

Tem-se, portanto, que a utilização dos vidros móveis fechados nas aberturas das varandas interfere sensivelmente no aumento da temperatura do ar interno ao ambiente, fazendo com que uma determinada orientação, mesmo que favorável sob o aspecto da arquitetura bioclimática, possa se tornar termicamente desconfortável. Além disso, o fato do monitoramento na Torre E ter sido realizado com os vidros móveis fechados sem proteção, resultou que os valores das médias das temperaturas do ar nesse ambiente fossem superiores quando comparados com as médias das temperaturas do ar encontradas na varanda da Torre D, cuja orientação é menos favorável, mas possui a proteção interna com cortinas de tecido tipo blackout.

O Gráfico 10 apresenta as médias de $24 \mathrm{~h}$ de umidade relativa do ar nas quatro semanas de monitoramento dos apartamentos das torres E e D. Observa-se que a cidade de Vitória apresenta altas taxas de umidade relativa do ar chegando a atingir no meio externo valores médios superiores a 79\% durante o período monitorado. Na condição dos vidros móveis abertos na varanda da Torre E, a umidade do ar teve valor máximo da média de $24 \mathrm{~h}$ de $71,27 \%$ no dia 24 de janeiro e um valor mínimo da média de 24 h de $65,51 \%$ no dia 27 de janeiro. Entretanto, quando os vidros móveis estavam fechados, a umidade relativa do ar na varanda decresce, provavelmente, devido ao aumento da temperatura no ambiente em função da condição de uso deste dispositivo, atingindo um valor mínimo da média de $24 \mathrm{~h}$ de 59,9\% ficando abaixo também dos valores obtidos na varanda da Torre D e nas salas. 

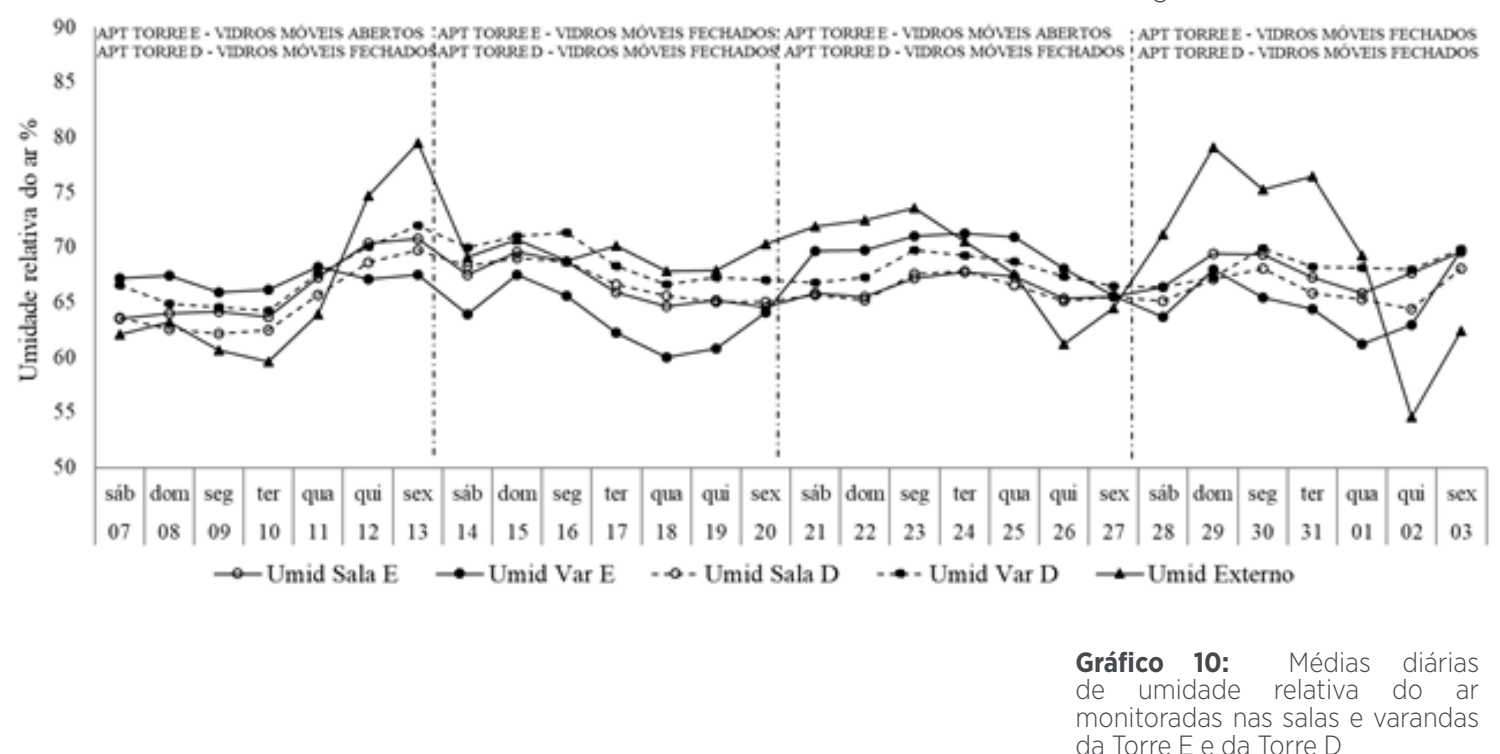

Fonte: Dos autores

Em relação à qualidade do ar observa-se que a máxima média de $24 \mathrm{~h}$ da concentração em massa de MP1, MP2,5, MP10 e PTS (2,62; 5,87; 15,61 e 28,71 $\mu \mathrm{g} / \mathrm{m}^{3}$ respectivamente) encontradas durante o período do monitoramento foi em dias de semana (quartas, quintas e sextas-feiras) com a situação dos vidros móveis da varanda do apartamento nordeste da Torre $\mathrm{E}$ fechados (Gráfico 11). Esses valores indicam juntamente com a contribuição de fontes internas, a importância do meio externo, principalmente veicular, na concentração de partículas, uma vez que há uma tendência de aumento no trânsito de veículos principalmente em função da proximidade com 0 final de semana. Santos et al. (2017) em seu estudo sobre o rateio de fontes do material sedimentado na RMGV afirma que as indústrias de aço e pelotização de minério de ferro são importantes contribuintes do material particulado na RMGV, entretanto, a ressuspensão do solo, construção civil e fontes veiculares são as principais fontes de poluição do ar para Jardim Camburi.

Os maiores valores encontrados com a condição dos vidros móveis da varanda fechados também mostram uma tendência em se ter concentrações significativas, no interior do ambiente, mesmo que uma pequena parte dos vidros móveis estejam abertos. Isso provavelmente porque na composição do material particulado a concentração numérica de partículas finas e ultrafinas é superior a concentração numérica de partículas com maior diâmetro (SEINFELD; PANDIS, 2006). Essas partículas menores possuem um maior tempo de residência na atmosfera e acabam ficando mais tempo em suspensão em ambientes com uma baixa taxa de renovação do ar. Esse resultado mostra que, ao contrário do que comumente se pensa, 0 ato de fechar as aberturas da varanda não contribui para uma efetiva melhoria da qualidade do ar interno, pois a concentração de partículas finas - que são mais prejudiciais à saúde humana, não sofre influência significativa do fechamento de varanda. Por outro lado, os resultados da percepção do material particulado avaliado pelos questionários aplicados aos moradores, mostra que o fechamento com vidros móveis, reduz o material particulado depositado no ambiente. Verifica-se, portanto, uma falsa sensação de melhoria em virtude da maior quantidade de partículas depositadas - e não em suspensão - quando os vidros móveis estão fechados e consequentemente, um menor incômodo. Entretanto, destaca-se o fato que as partículas inaláveis e de menores diâmetros continuam presentes no ambiente. 


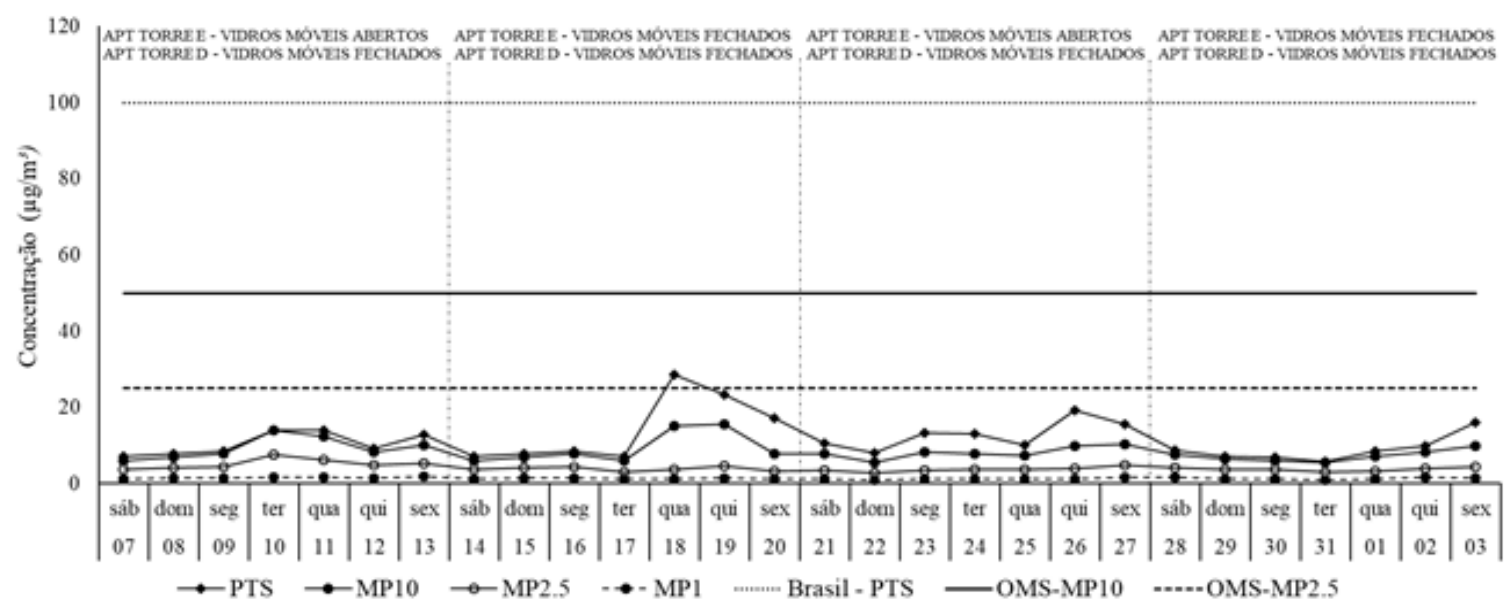

Gráfico 11: Médias diárias da concentração em massa de PTS (Partículas Totais em Suspensão), MP (Material Particulado com diâmetro abaixo de 10 microns), MP ${ }_{25}$ (Material Particulado com diâmetro abaixo de 2,5 microns) e MP (Material Particulado com diâmetro abaixo de 1 micron) obtidas na varanda do apartamento nordeste da Torre E, médias diárias da concentração em massa MP medido externamente pela Estação do IEMA e limites de exposição estabelecidos para PTS pela legislação nacional e para $\mathrm{MP}_{10}$ e $^{\mathrm{M} P_{2,5}}$ pela Organização Mundial de Saúde

Fonte: Dos autores

É importante ressaltar que, assim como a concentração externa (máxima média diária MP10 = 15,2 $\mu \mathrm{g} / \mathrm{m}^{3}$ ), os valores encontrados internamente estão abaixo do limite admitido pela legislação nacional e internacional. A legislação brasileira sobre qualidade do ar em interiores foi estabelecida para ambientes climatizados e determina limites de exposição em relação a MP apenas para PTS não considerando padrões para as partículas inaláveis (ANVISA, 2003). Os limites de $\mathrm{MP}_{10}$ e $\mathrm{MP}_{2,5}$ recomendados pela Organização Mundial da Saúde não são padrões, e sim diretrizes, estabelecidas originalmente para meio externos, que buscam nortear a instalação de padrões da qualidade do ar cuja responsabilidade na determinação e adaptação local é de cada país. O resultado deste trabalho reforça o fato já levantado por instituições e órgãos governamentais brasileiros para uma possível necessidade de revisão dos padrões da qualidade do ar (VALVERDE, 2018), uma vez que, mesmo com os valores atendidos, ainda assim há o incômodo à população ocasionado pelo material particulado sedimentado (MELO et al., 2015; SANTOS et al., 2017).

\section{RESULTADOS E DISCUSSÕES}

Este trabalho questiona a alteração na tipologia arquitetônica dos edifícios residenciais multifamiliares da cidade de Vitória, ES em consequência da crescente preferência pela população em fechar as aberturas das varandas com vidros móveis. Embora as questões para atenuação do ruído, proteção do vento e chuva foram apontadas como motivadoras do fechamento das aberturas das varandas por uma parcela significativa dos respondentes, o principal motivo de fechamento (82,6 \% dos respondentes) é em função do incômodo ocasionado pela presença do material particulado nas residências. A avaliação com os usuários mostrou que, embora a concentração de MP durante o monitoramento estava dentro dos limites estabelecidos pela legislação, uma parcela significativa $(52,2 \%)$ relata ter que limpar a casa todo dia em função do pó e que $68,5 \%$ declararam já terem tido problemas de saúde em decorrência da poeira.

Observa-se, ainda, que os participantes da pesquisa declararam a sensação de calor no ambiente, principalmente no período do verão, o que já era esperado, uma vez que se trata de uma cidade com clima quente e úmido e a utilização de um material, como o vidro, na envoltória promove a retenção da radiação solar nos ambientes internos. Consequentemente a maior parte 
dos respondentes declararam usualmente manter os fechamentos dos vidros móveis na condição "meio aberto" como forma de não perder a ventilação natural. Um fato adicional preocupante refere-se à declaração de 19,6\% dos moradores que afirmaram ter instalado ar condicionado na varanda em função do ganho de calor e como recurso adicional para melhoria do conforto térmico.

A medição dos parâmetros ambientais reitera o fato de que quando os vidros móveis estão abertos, a temperatura do ar interna da varanda se aproxima da temperatura do ar externo, garantindo maior quantidade de horas dentro da zona de conforto indicada, o que reforça a importância da ventilação natural como estratégia de condicionamento térmico passivo para climas tropicais quentes e úmidos. Entretanto, quando os vidros móveis das varandas estão fechados, para uma mesma quantidade de vapor de água no ar, o aumento de temperatura faz decrescer a umidade relativa do ar. Sabe-se que baixos índices de umidade relativa do ar podem ter efeitos adversos a saúde humana. A média diária da temperatura do ar no período monitorado foi elevada em até $3,83^{\circ} \mathrm{C}$ em relação a média diária da temperatura do ar obtida externamente no monitoramento da varanda sem proteção interna, atingindo a máxima média diária de $30,97^{\circ} \mathrm{C}$, acima da zona de conforto recomendada.

Em relação aos resultados do monitoramento do material particulado os maiores valores da concentração média diária foram registrados em dias de semana e com a condição dos vidros móveis fechados, o que mostra que juntamente com a contribuição de fontes internas, tem-se a influência dos poluentes gerados externamente, principalmente do tráfego veicular, na concentração do material particulado domiciliar. Ressalta-se que na percepção dos moradores o fechamento da abertura da varanda com vidros móveis reduz a quantidade de material particulado depositado internamente. Entretanto, chama-se a atenção para a presença das partículas menores, inaláveis, que tem um tempo de residência maior no ambiente e que mesmo em baixas concentrações podem causar danos à saúde devido a maior facilidade de penetração no trato respiratório humano. Estudos sobre a poluição atmosférica e os efeitos na saúde da população (DAPPER; SPOHR; ZANINI, 2016) têm demonstrado que, mesmo quando os poluentes se encontram abaixo dos níveis determinados pela legislação, estes são capazes de provocar efeitos na saúde das pessoas.

\section{REFERÊNCIAS}

\section{ABNT - ASSOCIAÇÃO BRASILEIRA DE NORMAS TÉCNICAS. NBR 15575- 1 Edificações Habitacionais - Desempenho Parte 1: Requisitos gerais. Rio de Janeiro, 2013.}

AFLAKI, Ardalan; MAHYUDDIN, Norhayati; MAHMOUD, Zakaria Alcheikh. A review on natural ventilation applications through building fac components and ventilation openings in tropical climates. Energy \& Buildings, v. 101, p.153-162, 2015. Disponível em: http:// dx.doi.org/10.1016/j.enbuild.2015.04.033.

ANNESI-MAESANO, Isabella et al. Residential proximity fine particles related to allergic sensitisation and asthma in primary school children. Respiratory Medicine, v. 101, n. 8, p. 1721-1729, 2007.

ANVISA - AGÊNCIA NACIONAL DE VIGILâNCIA SANITÁRIA. Resolução - RE no 9, de 16 de janeiro de 2003. Brasil: Diário Oficial da União, 2003

\section{ASHRAE STANDARD. Thermal Environmental Conditions for Human Occupancy. Atlanta, 2013}

BARBOSA, Miriam Jerônimo; WEILLER, Giovana CristianaBuso; LAMBERTS, Roberto. Disposição dos equipamentos para medição da temperatura do ar em edificações. Ambiente Construído, v. 7, n. 48, p. 89-108, 2007.

BRANDÃO, Helena Câmara Lacé; MARTINS, Angela Maria Moreira. A Varanda e suas contribuições para a Sustentabilidade. São Paulo: Núcleo de Pesquisas em Tecnologia da Arquitetura e Urbanismo da Universidade de São Paulo, 2007

CANDIDO, Christhina; DEAR, Richard De. From thermal boredom to thermal pleasure: a brief literature review. Ambiente Construído, v. 12, p. 81-90, 2012.

COUZEMENCO, Fernanda. Pó preto aumenta e população pede socorro 
ao prefeito de Vitória. Disponível em: http://seculodiario.com.br/36330/10/ po-preto-aumenta-e-populacao-pede-socorro-literalmente-ao-prefeito-de-vitoria. Acesso em: 27 jun. 2018.

DAPPER, Steffani Nikoli; SPOHR, Caroline; ZANINI, Roselaine Ruviaro. Poluição do ar como fator de risco para a saúde: uma revisão sistemática no estado de São Paulo. Estudos Avançados, v. 30, n. 86, p. 83-98, 2016. Disponivel em: http://dx.doi.org/10.1590/ S0103-40142016.00100006

EN ISO - THE EUROPEAN STANDARDIZATION. EN ISO 28802:2012

Ergonomics of the physical environment - an environmental survey involving. Dublin: National Standards Authority of Ireland, 2012

FREITAS, Clarice Umbelino de et al. Air pollution and its impacts on health in Vitoria, Espirito Santo, Brazil. Revista de Saúde Pública, v. 50, n. 0,2016. Disponíve em: $\quad$ http://www.scielo.br/scielo. php?script=sci arttext\&pid=S0034$89102016000100202 \&$ Ing=en\&tIng=em

GALWAN. Residencial Jardins Disponível em: https://www.galwan. com.br/imoveis/residencial-jardins/. Acesso: 27 jun. 2018.

G1. Relatório com 191 metas para reduzir pó preto na Grande Vitória é entregue para Vale e ArcelorMittal Disponível em: https://g1.globo.com/es/ espirito-santo/noticia/relatorio-com191-metas-para-reduzir-po-preto-nagrande-vitoria-e-entregue-para-vale-earcelormittal.ghtml. Acesso em: 27 jun. 2018.

GODISH, Thad. Air Quality. 4th editio ed. Chelsea, Michigan: Lewis Publishers, 2003.

HILLIAHO, Kimmo; NORDQUIST, Birgitta; et al. Energy saving and indoor climate effects of an added glazed facade to a brick wall building: Case study. Journal of Building Engineering, v. 7, p. 246262, 2016. Disponivel em: http://dx.doi. org/10.1016/j.jobe.2016.07.004.

HILLIAHO, Kimmo; KOVALAINEN, Ville; et al. Glazed spaces: A simplified calculation method for the evaluation of energy savings and interior temperatures. Energy \& Buildings, V. 125, p. 27-44, 2016. Disponível em: http:// dx.doi.org/10.1016/j.enbuild.2016.04.063

HILLIAHO, Kimmo; LAHDENSIVU, Jukka; VINHA, Juha. Glazed space thermal simulation with IDA-ICE 4.61 software - Suitability analysis with case study. Energy \& Buildings, v. 89, p. 132141, 2015. Disponível em: http://dx.doi. org/10.1016/j.enbuild.2014.12.041.

HILLIAHO, Kimmo; MÄKITALO, Eerik; LAHDENSIVU, Jukka. Energy saving potential of glazed space: Sensitivity analysis. Energy \& Buildings, v. 99, p. 87-97, 2015. Disponível em: http://dx.doi. org/10.1016/j.enbuild.2015.04.016

IBGE - INSTITUTO BRASILEIRO DE GEOGRAFIA E ESTATÍstICA. Senso 2010. Disponível em: www.ibge.gov.br. Acesso em: 6 jun. 2016.

IEMA - INSTITUTO ESTADUAL DE MEIO AMBIENTE E RECURSOS HÍDRICOS. Qualidade do ar. Disponivel em: https:// iema.es.gov.br/qualidadedoar. Acesso em: 22 jun. 2018.

INMET - INSTITUTO NACIONAL DE METEOROLOGIA. Estações automáticas. Disponível em: http:// www.inmet.gov.br/portal/index. php?r=estacoes/estacoesautomaticas. Acesso em: 7 jan. 2017.

ISO - INTERNATIONAL ORGANIZATION FOR STANDARDIZATION. ISO 7726 - Ergonomics of the thermal environment -- Instruments for measuring physical quantities. Genove: [s.n.], 1998

JORGE, Liziane De Oliveira. Estrategias de Flexibilidade na Arquitetura Residencial Multifamiliar. Tese (Tese em Arquitetura e Urbanismo) - Universidade de São Paulo. São Paulo, 511 f., 2012.

MATTIUZZI, Henrique Vescovi; MARCHIORO, Eberval. O comportamento dos ventos em Vitória (ES): a gestão e interpretação dos dados climatológicos. Revista Geonorte, v. 2, n. 4, p. 983-993, 2012.

MELO, Milena $M$ et al. Annoyance Caused by Air Pollution: A Comparative Study of Two Industrialized Regions. International Journal of Environmental and Ecological Engineering, v. 9, n. 2, p. 177-182, 2015.

MIOT, Hélio Amante. Tamanho da amostra em estudos clínicos e experimentais. Jornal Vascular Brasileiro, v. 10, n. 4, p. 275-278, 2011.

NICO-RODRIGUES, Edna Aparecida et al. Quando a janela define a condição de desempenho térmico em ambientes ventilados naturalmente: caso específico das edificações multifamiliares em Vitória, ES. Ambiente Construído, v. 15, p. 7-23, 2015. 
NICOLUSSI, Francine Heloisa et al. Poluição do ar e doenças respiratórias alérgicas em escolares. Revista de Saúde Pública, v. 48, n. 2, p. 326-330, 2014. Disponível em: http://www.scielo.br/scielo.php?script=sci_arttext\&pid=S0034-89102014000200326\&lng=pt\&tlng=pt.

NOBRES, Juirana et al. Entenda o que é o pó preto que polui o ar e o mar de Vitória há anos Samarco, Acellor Mittal e Vale são apontadas como principais poluidoras. Disponível em: http://g1.globo.com/espirito-santo/noticia/2016/01/ entenda-o-que-e-o-po-preto-quepolui-o-ar-e-o-mar-de-vitoria-ha-anos. html. Acesso em: 27 jun. 2018.

PAGEL, É.C. et al. Indoor air quality in an Antarctic Research Station: Fungi, particles and aldehyde concentrations associated with building materials and architectural design. Indoor and Built Environment, 2017.

PMV - PREFEITURA MUNICIPAL DE VITÓRIA. Lei 6801 Seção III do capítulo V da Lei $\mathbf{4 8 2 1}$ de $\mathbf{3 0}$ de dezembro de 1998. Vitória, 2006

PMV - PREFEITURA MUNICIPAL DE VITÓRIA. Lei $\mathbf{N}^{\circ} \mathbf{4 8 2 1}$ Código de Edificações do Município de Vitória. Vitória, 1998

SALEH, Philip H. Thermal performance of glazed balconies within heavy weight / thermal mass buildings in Beirut, Lebanon's hot climate. Energy \& Buildings, v. 108, p. 291-303, 2015. Disponível em: http://dx.doi. org/10.1016/j.enbuild.2015.09.009.

SALKINI, Hadya; GRECO, Laura; LUCENTE, Roberta. Towards adaptive residential buildings traditional and contemporary scenarios in bioclimatic design ( the case of Aleppo ). Procedia Engineering, V. 180, p. 1083-1092, 2017. Disponível em: http://dx.doi. org/10.1016/j.proeng.2017.04.268.

SANTOS, J. M. et al. Experimental investigation of outdoor and indoor mean concentrations and concentration fluctuations of pollutants. Atmospheric Environment, v. 45, n. 36, p. 65346545, 2011. Disponível em: http://dx.doi. org/10.1016/j.atmosenv.2011.08.049.

SANTOS, Jane Meri et al. Source apportionment of settleable particles in an impacted urban and industrialized region in Brazil. Environmental Science and Pollution Research, v. 24, n. 27, p. 22026-22039, 2017.
SCHIRMER, Waldir Nagel et al. A poluição do ar em ambientes internos e a síndrome dos edifícios doentes. Ciência \& Saúde Coletiva, v. 16, n. 8, p. 3583-3590, 2011.

SEINFELD, John $H$; PANDIS, S N. Atmospheric Chemistry and Physics From Air Pollution to Climate Change SECOND EDI ed. Hoboken, New Jersey: John Wiley \& Sons, Inc., 2006.

SILVA, Marielle Ferreira et al. Postoccupancy evaluation of residential buildings in Luxembourg with centralized and decentralized ventilation systems, focusing on indoor air quality (IAQ): assessment by questionnaires and physical measurements. Energy \& Buildings, 2017. Disponível em: http:// dx.doi.org/10.1016/j.enbuild.2017.04.049.

SPIRU, Paraschiv; SIMONA, Paraschiv Lizica. ScienceDirect ScienceDirect A review on interactions between energy performance of the buildings, outdoor air pollution and the indoor air quality. Energy Procedia, v. 128, p. 179-186, 2017 Disponível em: https://doi.org/10.1016/j. egypro.2017.09.039.

TEIXEIRA, Fábio. Prefeito deve sancionar lei que permite o fechamento de varandas. Disponível em: http:// oglobo.globo.com/rio/bairros/prefeitodeve-sancionar-lei-que-permitefechamento-de-varandas-13267849. Acesso em: 6 jun. 2016.

TOLEDO, Alexandre Marcio; COSTA, Isabely Penina C. da;; BULHÕES, Michelle Carolline S. Usuários fecham as varandas dos apartamentos da Orla de Maceió : adequação aos novos usos ou inadequação ao clima? Gestão \& Tecnologia de Projetos, v. 5, n. 2, p. 131-154, 2010.

VALVERDE, Ricardo. Meio ambiente debate revisão dos padrões de qualidade do ar. Disponível em: https:// agencia.fiocruz.br/meio-ambientedebate-revisao-dos-padroes-dequalidade-do-ar. Acesso em: 16 nov. 2018.

VICTORIA, Janet et al. Bioclimatic design approach in Dayak traditiona longhouse. Procedia Engineering, v. 180, p. 562-570, 2017. Disponível em: http:// dx.doi.org/10.1016/j.proeng.2017.04.215.
Erica Coelho Pagel erica.pagel@gmail.com

Cristina Engel de Alvarez

Neyval Costa Reis Júnior 
